\title{
SYNTHESIS AND ANALYSIS OF NOVEL POLYMERS WITH HIGH PERMSELECTIVITY AND PERMEABILITY IN GAS SEPARATION APPLICATIONS
}

\author{
Final Report
}

\author{
Submitted by \\ W. J. Koros and D. R. Paul \\ Department of Chemical Engineering \\ The University of Texas at Austin \\ Austin, Texas 78712-1062 \\ (512) $471-5866$ \\ (512) $471-5392$
}

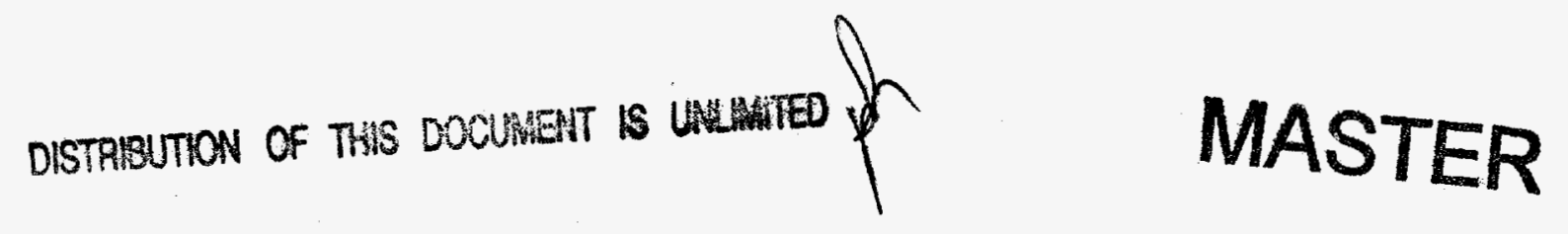

May 1, 1995

PREPARED FOR THE U.S. DEPARTMENT OF ENERGY UNDER CONTRACT NUMBER: DE-FG05-86ER13507 


\section{DISCLAIMER}

This report was prepared as an account of work sponsored by an agency of the United States Government. Neither the United States Government nor any agency thereof, nor any of their employees, make any warranty, express or implied, or assumes any legal liability or responsibility for the accuracy, completeness, or usefulness of any information, apparatus, product, or process disclosed, or represents that its use would not infringe privately owned rights. Reference herein to any specific commercial product, process, or service by trade name, trademark, manufacturer, or otherwise does not necessarily constitute or imply its endorsement, recommendation, or favoring by the United States Government or any agency thereof. The views and opinions of authors expressed herein do not necessarily state or reflect those of the United States Government or any agency thereof. 


\section{DISCLAIMER}

Portions of this document may be illegible in electronic image products. Images are produced from the best available original document. 


\section{Summary of Activities}

During the three years of support under our grant, DOE-FG05-86ER13507, ten novel polymer structures have been synthesized and characterized in detail in terms of sorption and transport properties to test our hypotheses on strategies to develop advanced materials for gas separation membranes. The extremely important $\mathrm{O}_{2} / \mathrm{N}_{2}$ and $\mathrm{CO}_{2} / \mathrm{CH}_{4}$ systems have been the focus of our work. Six $\mathrm{PhD}$ students were supported by the grant during the their studies. Several of them went on to accept positions with companies developing the commercial aspects of this new field. Funds to leverage DOE support were also provided by a University-Industry consortium at the University of Texas. This consortium, called the Separations Research Program, allowed leveraging the DOE funds by helping to cover supply and equipment costs. A total of twenty refereed papers were generated during the grant, and these are listed at the end of this report.

\section{More Details on Activities Noted Above}

In earlier papers, our group has developed guidelines and principles to assist in the optimum development of tradeoffs between permeability and selectivity [1-5]. Application of these principles have resulted in several attractive materials for gas separation for $\mathrm{O}_{2} / \mathrm{N}_{2}$ and $\mathrm{CO}_{2} / \mathrm{CH}_{4}$ systems. A comprehensive review by Robeson [6] defines the current situation in the membrane-based gas separation materials field. Our most recent work shows that similar principles, developed in our work with polycarbonates and polysulfones appear to apply to the polyarylate family as well. Specifically, counterbalancing the effects of packing disruptive substitutions with segmental mobility adjustments by control of pendant groups and isomer types allows optimizing polyarylate properties very effectively.

Data for permeabilities and permselectivities for $\mathrm{O}_{2} / \mathrm{N}_{2}$ and $\mathrm{CO}_{2} / \mathrm{CH}_{4}$ at $35^{\circ} \mathrm{C}$ at approximately $2 \mathrm{~atm}$ feed pressure for $\mathrm{O}_{2} \& \mathrm{~N}_{2}$ and $10 \mathrm{~atm}$ for $\mathrm{CO}_{2} \& \mathrm{CH}_{4}$ are reported in Tables 1 and 2 and will be discussed in two parts, one related to each of the groups of structures in these two tables. For the sake of efficiency, we will only consider the $\mathrm{O}_{2} / \mathrm{N}_{2}$ data; however, similar trends apply for the $\mathrm{CO}_{2} / \mathrm{CH}_{4}$ system as well. This gas pair is useful, since solubility selectivity effects are generally of much smaller importance than for the $\mathrm{CO}_{2} / \mathrm{CH}_{4}$ pair, so even without detailed solubility and diffusivity data, mobility selectivity based arguments tend to be adequate. 
Table 1: Materials focusing primarily on bisphenol-A based structures.

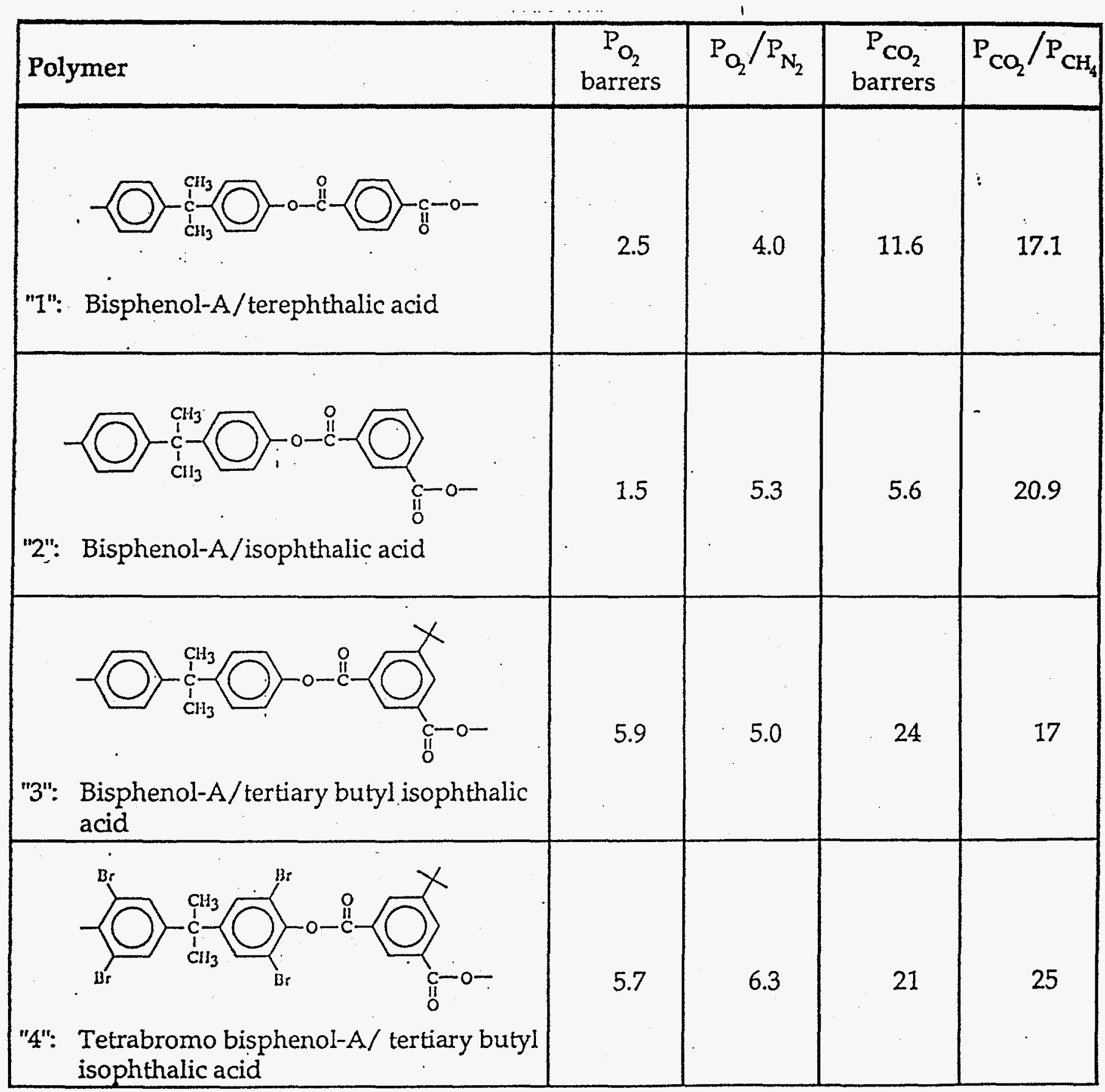


Table 2: Materials focusing primarily on phenolphthalein-based and fluorene-based structures.

\begin{tabular}{|c|c|c|c|c|}
\hline Polymer & $\begin{array}{c}\mathrm{P}_{\mathrm{O}_{2}} \\
\text { barrers }\end{array}$ & $\mathrm{P}_{\mathrm{O}_{2}} / \mathrm{P}_{\mathrm{N}_{2}}$ & $\begin{array}{c}\mathrm{P}_{\mathrm{CO}_{2}} \\
\text { barrers }\end{array}$ & $\mathrm{P}_{\mathrm{CO}_{2}} / \mathrm{P}_{\mathrm{CH}_{4}}$ \\
\hline "1": Bisphenol-A/terephthalic acid & 2.5 & 4.0 & 11.6 & 17.1 \\
\hline $\begin{array}{l}\text { "5": Phenolphthalein/terephthalic acid } \\
\text { [from Chern, I. M.Sci.,59, 292 (1991)] }\end{array}$ & 3.2 & 4.9 & 17.2 & 27.0 \\
\hline "6": Phenolphthalein/isophthalic acid & 1.5 & 5.5 & 6.7 & 40.0 \\
\hline "7": $\begin{array}{l}\text { Tetra bromo phenolphthalein/ } \\
\text { isophthalic acid }\end{array}$ & 2.1 & 6.9 & 9.7 & 44.0 \\
\hline "8": $\begin{array}{l}\text { Tetra bromo phenolphthalein/tertiary } \\
\text { butyl isophthalic acid }\end{array}$ & 7.7 & 6.3 & 34 & 27 \\
\hline 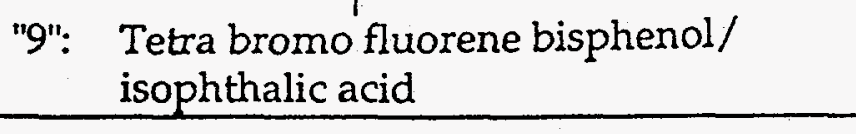 & 4.8 & 6.9 & 20.4 & 36 \\
\hline "10": Tetra bromo fluorene bisphenol/t- & 16.8 & 5.7 & 69.5 & 25.1 \\
\hline
\end{tabular}


Figure 1, corresponding to the data in Table 1, shows the tradeoff curve for the $\mathrm{O}_{2} / \mathrm{N}_{2}$ system at $35^{\circ} \mathrm{C}$ with the area below the line typical of commercially available glassy or rubbery materials. This solid line was determined by an extensive review of the existing literature about ten years ago in preparation of our original proposal to DOE. The dashed line at the top of the figure corresponds to the current boundary above which no structures yet exist in the open literature. This line was taken from the extensive review by Robeson [6] of the state of the art of the field and provides a useful limit against which to compare.

The first set of structures considered consists of the series of polyarylates shown in Table 1 and in Figure 1 are structures "1"-"4" and correspond to: "1"[bisphenol-A/terephthalic acid], "2"[bisphenolA/isophthalic acid], "3"[bisphenol-A/t-butyl isophthalic acid] and "4"[tetrabromo bisphenol-A/t-butyl isophthalic acid]. Consider the dotted line arrows describing a "trajectory" on the tradeoff plot from "1"$\rightarrow " 2 "$. In this case, replacement of the para connection (tere) which can undergo relatively free movement at its collinear backbone connections by the noncollinear iso connection causes the selectivity to rise with some loss in productivity due to increased impedance of segmental motion. Although clearly not near the upper bound property line, such a result is still desirable, since " 2 " lies favorably off the tradeoff line as opposed to the starting point structure "1". Continuing from "2" to "3" illustrates the effects of introducing the large packing-inhibiting t-butyl spacer group on the motionally hindered isophthalic acid. A small loss in selectivity occurs, while the permeability rises greatly, actually exceeding that for the starting material "1". Proceeding still further from "3" to "4", illustrates the strong effects of introducing polar attractions within the matrix to hinder segmental motion. Unlike the tere---> iso change, the tetrabromo substitution drives selectivity up sharply with almost no loss in permeability. The "4" point lies rather close to the upper bound limit properties. This series shows the advantage of not only inhibiting motion (tere --> iso) but also simultaneously inhibiting packing (iso --> t-butyl iso change) and introduction of polar units (bisphenol A $-\rightarrow>$ tetrabromo bisphenol A). 

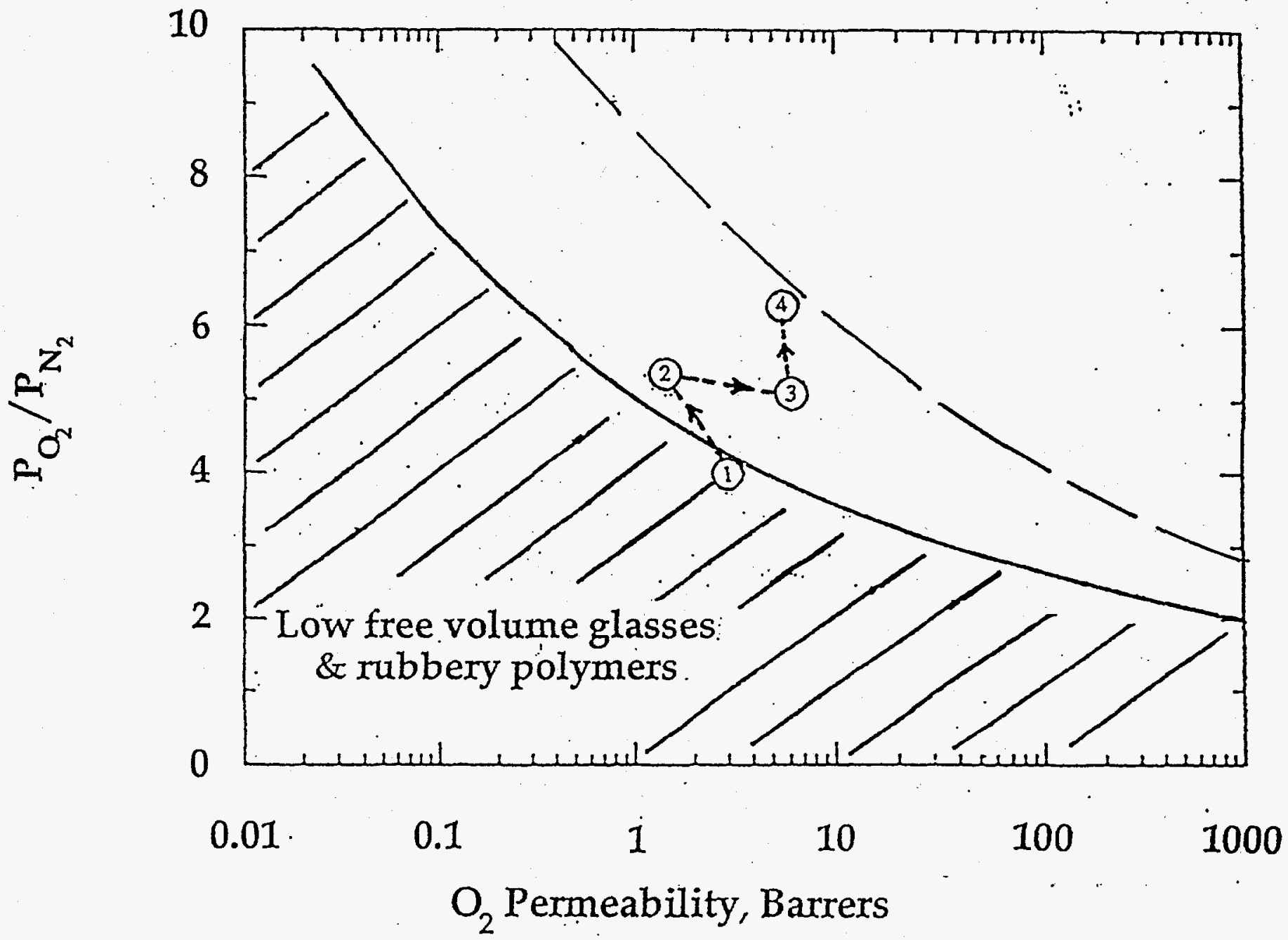

Figure 1: Permeability-Selectivity Tradeoff Relationship for the oxygennitrogen system with a "trajectory" formed by consideration of the structures "1"-" 4 " in Table 1. The signficance of the solid and dashed boundaries in the figure are discussed in the text. 
A second, interesting group of structures consists of the series shown in Table 2 and in Figure 2 corresponding to: "1"[bisphenol-A-terephthalic acid], "5"[phenolphthalein/terephthalic acid], "6"[phenolphthalein/ isophthalic acid], "7"[tetrabromo-phenolphthalein/isophthalic acid], and "8"[tetrabromo phenolphthalein/t-butyl isophthalic acid], "9"[tetrabromo fluorenebisphenol/isophthalic acid], and "10"[tetrabromo fluorenebisphenol/t-butyl isophthalic acid]. In this series, as shown by the dotted line arrows in Figure 2, replacement of the "mobile" bisphenol A with the noncollinear and highly packing inhibited phenolphthalein causes the permeability and selectivity to rise favorably off the standard tradeoff line (see "1" -->"5"). Proceeding further from "5" to "6" involves replacement of the para connection (tere) with the noncollinear iso connection. This change causes a similar tradeoff with higher selectivity and a loss in productivity like that seen in the first group ("1" --> "2"), supporting the generality of the hypothesized effect. Proceeding still further from "6" --> "7", illustrates the strong effects of introducing polar attractions within the matrix to hinder segmental motion. Unlike the tere--> iso change, the tetrabromo substitution drives selectivity and permeability up. Applying the lessons learned in the previous set of structures and proceeding from "7" --> " 8 " with the introduction of the large t-butyl spacer group on the motionally hindered isophthalic group we find an expected small loss in selectivity, while the permeability rises well above that for the starting material "1".

In Figure 2, Point "8" point actually lies on the upper bound limit property line, while retaining the ability to be processed with current asymmetric membrane technology! The step from " 8 " -$>$ "9" gives the first hint of the beneficial effects on selectivity due to incorporation of large flat units in the polymer by considering the fluorene-based bisphenol arylate structure. This theme is developed further in a following section. Finally, the step from "9" --> "10" reaffirms the packing disruptive utility of the t-butyl group illustrated earlier with both the bisphenol-A and the phenolphthalein materials noted above.

Although other series can also be considered, the structures in Tables 1 and 2 suffice to show that one sees the same intuitively reasonable behavior in the polyarylates as we found in the polycarbonate and polysulfone families earlier (see last section in this report for a list of publications citing DOE support). The proceeding examples illustrate the exciting utility of the emerging data base for understanding the desirability of a particular structural change relative to a starting material, e.g., 

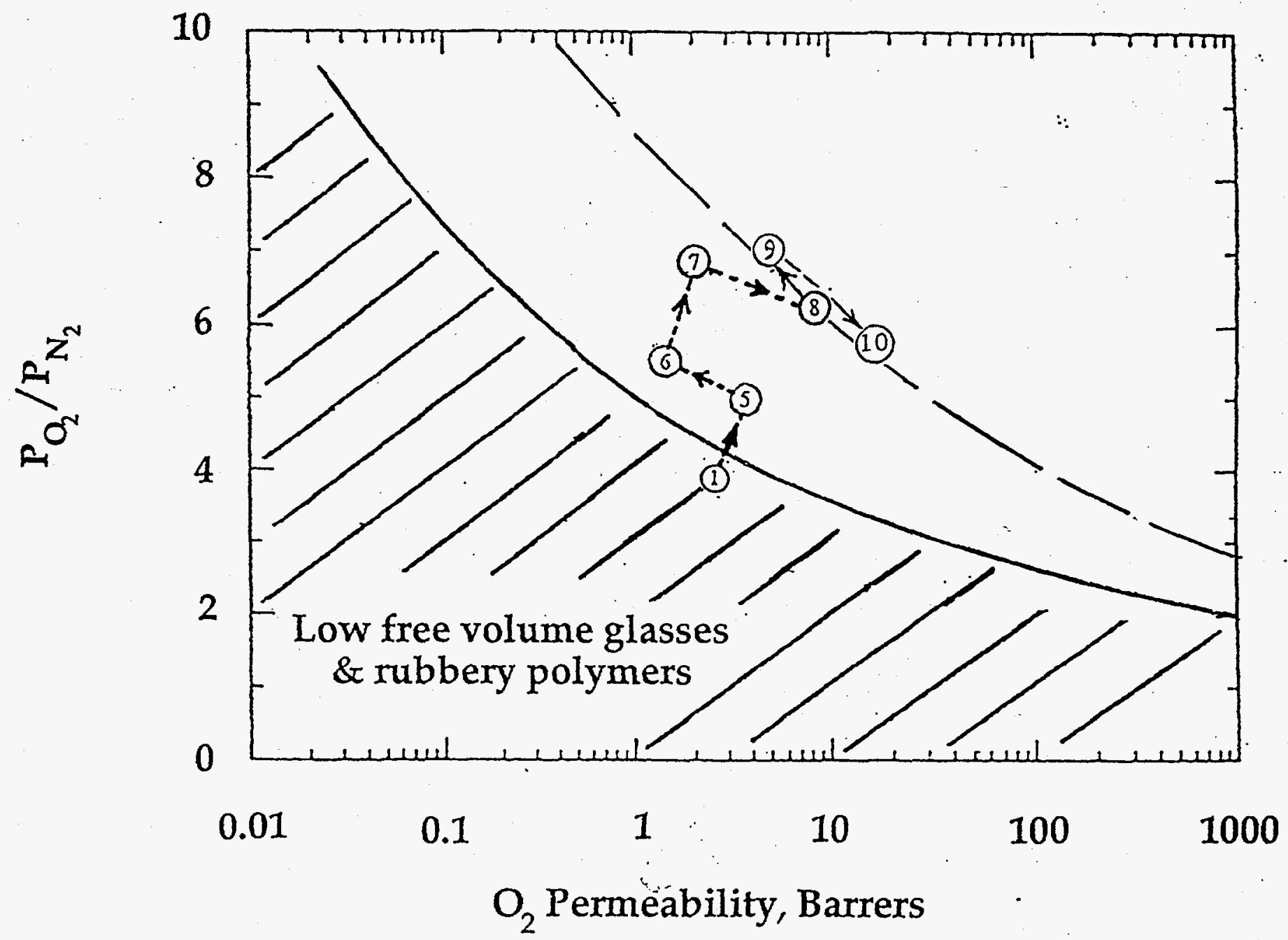

Figure 2: Permeability-Selectivity Tradeoff Relationship for the oxygennitrogen system with a "trajectory" formed by consideration of the structures " 1 "-" 10 " in Table 2. The signficance of the solid and dashed boundaries in the figure are discussed in the text. 
structure "1" vs. structure "10" in Fig. 2. This is a significant achievement in its own right and provides industry with a useful instrument to guide the ongoing search for improved materials.

In many cases, such as the discussion of Figs. 1 and 2, analyses of structure-property behavior are confined to a given polymer family. This approach avoids confusion associated with cross-family differences in mobility around the hetero-atom linkage (carbonate, ether, imide, etc.) characteristic of each family and allows illustrating obvious principles as was demonstrated in the above discussion.

\section{References}

1. W. J. Koros and G. K. Fleming, J. Membr. Sci., 83; 1 (1993).

2. W. J. Koros, M. R. Coleman, and D. R. B. Walker, "Controlled Permeability Polymer Membranes", in Annual Review of Materials Science, Vol. 22, pp. 47-90, 1991.

3. W. J. Koros and D. R. B. Walker, Polymer Journal (Japan), 23, 481 (1991).

4. M. W. Hellums, W. J. Koros, G. R. Husk, and D. R. Paul, J. Appl. Polym. Sci., 43, 1977 (1991).

5. D. R. Paul and C. L. Aitken, J. Polym. Sci., Phys. Ed., 31, 1061 (1993).

6. L. Robeson, J. Membr. Sci., 62, 165 (1991). 


\section{PUBLICATIONS ACKNOWLEDGING DOE SUPPORT \\ UNDER GRANT DE-FG05-86ER13507 \\ Published Since Last Renewal}

1. Koros, W. J., M. W. Hellums and D. R. Paul, "Gas Transport in Halogen-Containing Aromatic Polycarbonates", J. Appl. Polym. Sci., 43, 1977 (1991).

2. Hellums, M. W., Koros, W. J., and Schmidhauser, J. C., "Gas Separation properties of spirobiindane polycarbonate", J. Membr. Sci., 67, 75 (1992).

3. McHattie, J. S., W. J. Koros and D. R Paul, "Gas Transport of Polysulfones. Part III: Comparison of Tetramethyl Substituted Bisphenols", Polymer; 33, 1701 (1992).

4. Aitken, C. L., W. J. Koros and D. R. Paul, "Effect of Structural Symmetry on Gas Transport Properties of Polysulfones", Macromolecules, 25, 3425 (1992).

5. Aitken, C. L., W. J. Koros and D. R. Paul, "Gas Transport Properties of Bisphenol Polysulfones", Macromolecules, 25, 3651 (1992).

6. Costello, L. M. and W. J. Koros, "Temperature Dependence of Gas Sorption and Transport Properties in Polymers: Measurement and Applications", Ind. \& Engr. Chem. Res., 31, 2708 (1992).

7. Aitken, C. L., D. K. Mohanty and D. R. Paul, "Gas Transport Properties of Poly(arylether bissulfone)s and Poly(arylether bisketone)s", J. Polym. Sci: Polym. Phys., 31, 983 (1993).

8. Aitken, C. L. and D. R. Paul, "Gas Transport Properties of Polysulfones Based on Dihydroxynaphthalene Isomers", J. Polym. Sci.: Polym. Phys., 31, 1061 (1993).

9. $\quad$ Aguilar-Vega, M. and D. R. Paul, "Gas Transport Properties of Polyphenylene Ethers", J. Polym. Sci.: Part B: Polym. Phys., 31, 1577 (1993).

10. Aguilar-Vega, M. and D. R. Paul, "Gas Transport Properties of Polycarbonates with Aromatic Substitutions on the Bisphenol Connector Group", J. Polym. Sci.: Part B: Polym. Phys., 31 , 1599 (1993).

11. Costello, L. M. and W. J. Koros, "Comparison of Pure and Mixed $\mathrm{Gas}_{2} \mathrm{CO}_{2}$ and $\mathrm{CH}_{4}$ Permeabilities in Polycarbonate: Effect of Temperature", Ind. \& Engr. Chem. Res., 32, 2277 (1993).

12. Pessan, L. A. and W. J. Koros, "Isomer Effects on Transort Properties of Polyesters Based on Bisphenol-A", J. Polym. Sci., Polym. Phys., 31, 1245 (1993).

13. Costello, L. M. and W. J. Koros, "Effect of Structure on the Temperature Dependence of Gas Transport and Sorption in a Series of Polycarbonates", J. Polym. Sci.: Part B: Polym. Phys., 32, 701 (1994).

14. Costello, L. M., D. R. Walker and W. J. Koros, "Analysis of a Thermally-Stable Polypyrrolone for High Temperature Membrane-Based Gas Separations", J. Membr. Sci., 90, 117 (1994).

15. Coleman, M. R., R. Kohn and W. J. Koros, "Gas Separation Application of Miscible Blends of Isomeric Polyimides", J. App. Polym. Sci., 50, 1059 (1993).

16. Hagg, M. -B, W. J. Koros and J. C. Schmidhauser, "Gas Sorption and Transport Properties of Bisphenol-I-Polycabonate", J. Polym. Sci., Polym. Phys., 32, 1625 (1994). 
17. Coleman, M. R. and W. J. Koros, "The Transport Properties of Polyimide Isomers Containing Hexafluoroisopropylidene in the Diamine Residue", J. of Polym Sci., 32, 1915 (1994).

\section{Publications in Press}

18. Pfromm, Peter and W. J. Koros, "Accelerated physical aging of thin glassy polymer films: Evidence from gas transport measurements", Polymer, in press.

19. Pessan, L. A., W. J. Koros, J. C. Schmidhauser and W. D. Richards, "Gas transport properties of polymers based on spirobiindane bisphenol", J. Polym. Sci., Polym. Phys., submitted.

20. Costello, L. M.and W.J. Koros, "Thermally-Stable Polyimide Isomers for Membrane-Based Gas Separations at Elevated Temperatures", J. Polym. Sci., Polym Phys., submitted. 